\title{
Monitoring of specific activities of long-lived radioactive elements along the Mini- Okoro/Oginigba Creek, Port Harcourt
}

\section{${ }^{1}$ GREGORY O. AVWIRI, ${ }^{2}$ *OLANREWAJU LAWAL, ${ }^{1}$ EDITH I. NWOKEOJI}

\author{
${ }^{1}$ Department of Physics, Faculty of Science, University of Port Harcourt, Port Harcourt, Rivers State \\ ${ }^{2}$ Department of Geography and Environmental Management, Faculty of Social Sciences, University of Port Harcourt, Port Harcourt, Rivers \\ State \\ *Corresponding author's contact: Tel.: +2349097347063; Email: olalaw@hotmail.com
}

\begin{abstract}
Presence and concentrations of radionuclides could be as a result of natural and human activities. This study examined the associations and differences among soil, sediment and water specific activities of long-lived radioactive element (LLRE). Gamma spectroscopy was used to measure the concentration of the LLRE along the Mini Okoro/Oginigba Creek, Port Harcourt. Specific activities of three selected LLRE were derived. Correlation analysis was carried out to examine associations among the specific activities across different substrates. A strong and a significant negative correlation exists between the specific activities of Water ${ }^{40} \mathrm{~K}$ and Soil ${ }^{232} \mathrm{Th}(\mathrm{r}=-0.721, \mathrm{p}<0.05)$; Water ${ }^{238} \mathrm{U}$ and Soil ${ }^{238} \mathrm{U}(\mathrm{r}=-0.717, \mathrm{p}<0.05)$ and Water ${ }^{40} \mathrm{~K}$ and Sediment ${ }^{238} \mathrm{U}(\mathrm{r}=-0.69, \mathrm{p}<0.05)$. Comparison using Mann-Whitney $\mathrm{U}$ test shows that, soil and sediment are similar in their specific activities with $Z$ values of $-0.408,-1.209$ and -1.021 (p $>0.05$ ) for ${ }^{40} \mathrm{~K},{ }^{232} \mathrm{Th}$ and ${ }^{238} \mathrm{U}$ respectively. The concentration of solid samples (soil and sediment) is different from the liquid (water) samples. These associations can be attributed to some specific underlying factors. And in other to understand them there is need for more studies. (C) JASEM
\end{abstract}

http://dx.doi.org/10.4314/jasem.v20i1.3

KEYWORDS: Radionuclide; environmental monitoring; Niger Delta; Gamma spectroscopy; Environmental management

\section{Introduction}

Human settlements such as cities and other urban settlements, create one of the most intense human interactions between humans and nature (Lawal, 2009). These interactions could be seen in the form of the continuous flow of resources and materials through the economy, which create both useful products and also create wastes which is often the cause of many of our environmental (Lawal, 2014) and health issues.

Radioactive materials could be naturally occurring radioactive materials (NORM) and technologically enhanced NORM (TENORM). Knowledge and understanding of the distribution of these is very important in assessing their potential health and environmental impacts. In nature, NORM concentration are usually dependent on the location and geological characteristics (United Nations. Scientific Committee on the Effects of Atomic Radiation, 2000). Processes (such as weathering, rainfall, and runoff) within the natural environment acting on rocks facilitate the enrichment and distribution of radionuclides in the soils. Therefore, their specific activity in the soil can be used as the natural background radiation. But, within the urban environment and other areas where human activities have impacted, such could be increased as a results of anthropogenic factors. These factors could be in the form of mining and combustion of coal; oil and gas production; metal mining and smelting; mineral sands, fertiliser industry; building industry and recycling- all of which tend to enhance NORM in the environment (World Nuclear Association, 2014).

The dominance of the oil and gas industry in Nigeria, makes it a very important industry along the coastal region of Nigeria. With this dominance is the attendant impacts on the environment, especially in relation to the potential enhancement of NORM across the coastal region. Thus, it could be said that the industries potentially increases TENORM concentration across this region. Looking at the peculiarities of the region, high annual rainfall, high water table (Nwankwoala and Omunguye, 2013) and shallows borehole/wells for potable water, minimal coverage of pipe borne water utility (Water and Sanitation Department, 2014) the risk to public health is quite significant. The industries and activities previously mentioned, utilises a considerable amount of NORM, which often end up in effluents originating from them all of which has a very high 
probability of ending up in water bodies (and or groundwater). This potentially has a negative impact on the quality and ecology of the water bodies. This understanding has resulted in the monitoring and regulation of some of these industries, although, there is a great deal of inconsistency in these regulations across countries and industries (World Nuclear Association, 2014).

In Nigeria, for example, there are significant issues with respect to public health and environmental management. These issues include lack of enforcement (zoning of industrial activities and effluent standards) and loose/inefficient regulatory framework as well as costs, equipment, coverage problems in monitoring the environment. Therefore, to address some of these issues there is a need to understand the dynamics and relationship among some of the environmental health indicators (in this case the specific activities of NORM/TENORM). This understanding can help in filling gaps in data and thus allow for local, regional and national modelling of NORM across the country, thereby supporting initiatives that could enhance environmental quality and quality of life across the country.

To this end, the objectives of the study is to:

- Examine the association among soil, sediment and water specific activity of selected radionuclides.

- Determine the differences among the specific activities of each radionuclide across substrates within the study area.

\section{MATERIALS AND METHODS}

Study Area: The study was carried out around the Mini-Okoro/Oginigba creek (Figure 1) located within the Trans-Amadi Industrial Area of Port Harcourt Metropolis. According to the Köppen-Geiger climate classification (Rubel and Kottek, 2010), the study area belongs to the Tropical Monsoonal climate. This is characterised by a short dry season and a pronounced wet season, with one or more months having less that $60 \mathrm{~mm}$ of rain. All months have mean monthly temperature greater than $18^{\circ} \mathrm{C}$ and the highest annual temperature is usually experienced just before the onset of the rainy season.

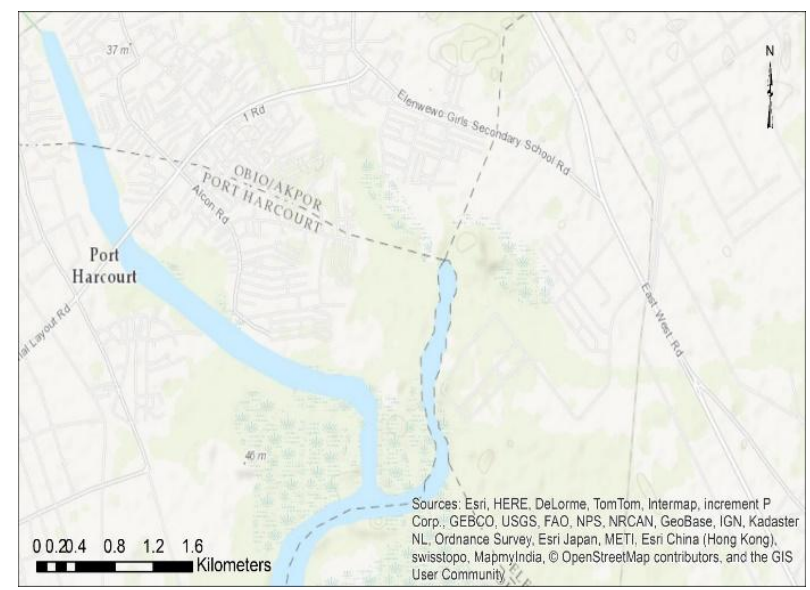

Fig 1: Topographic map of the location and features around the study area

This creek is located within Port Harcourt, Rivers State, one of the largest cities in the Niger Delta region of Nigeria. The State has three ecological zones - Mangrove forest and coastal vegetation; fresh water swamps and lowland rainforest with the Mangrove forest and coastal vegetation being the most dominant (Niger Delta Development Commission, 2006). The landmass is on a coastal plain belonging to the Niger Delta sedimentary formation (Short and Stauble, 1967). The terrain has slopes ranging between an average of 3 and 5 degrees towards the NW-SE direction, thus impacting on the drainage of the area (poorly drained, low relief and gentle slopes -consequently low river flow).
According to NDDC (2006), the pattern of settlement is influenced by availability of dry land and the nature of a big city like Port Harcourt on the mangrove swamp arises as a result of relatively better drainage conditions and accessibility. Furthermore, the majority of top soils $(60 \%)$ across the dominant ecological zones (Mangrove forests and Coastal Vegetation) in the State are of low fertility.

The Mini-Okoro Stream and the Oginigba Creek under study, drains the Freshwater swamp forest into Woji Creek which drains into the Bonny Estuary. The stream is shallow and joins up with the Oginigba Creek (a shallow, brackish, around 4km long and 100 
$-200 \mathrm{~m}$ width), together emptying into the Bonny River (eventually the Estuary). Situated along this water body are sawmills, Shell Petroleum Development Company, Pabod Breweries, Nigerian Bottling Company, Schlumberger and many other oil servicing companies. Furthermore, it is known that the breweries discharge their effluent into the creek as well as the old Michelin Tyre manufacturing company (no longer active). Other activities and industries along the water body includes, boat building, welding and metallurgy, abattoirs, block moulding (sand collection from stream), petrol stations, electrical substations, household waste dumping in the stream all contributed to polluting the stream.

Data Collection: Sodium-Iodide Scintillation detector was used to measure the specific activity concentration for the LLRE selected in the samples collected from the study area. This method was adopted because there is no need for chemical separation before taking reading. It is also highly efficient and relatively cost effective (however energy resolution in not very good). Sampling started from the Rumuobiakani Bridge down to the TranAmadi Slaughter bridge (behind Port Harcourt Zoo). 30 samples were collected along this route (ten each for soil, water and sediment).

Water samples were collected using two litres plastic bottles. Prior to collection, plastic bottles were rinsed with the sample water to minimise contamination. Samples were collected on the banks of the stream (less dilution of the washout). Acidification was carried out using $0.1 \mathrm{M}$ of Dilute $\mathrm{HCl}$ at the rate of $10 \mathrm{ml}$ per litre of water sample. This minimises precipitation on and prevent absorption by the walls of the plastic bottle used. Sample bottles were tightly capped and labelled accordingly with space left for expansion. Sample were transferred in the Marinelli sample containers and stored for four weeks. After this storage gamma spectroscopy was then carried out on the samples.

At a depth of between 10 and $15 \mathrm{~cm}$, soil and sediment were collected. Samples collected, were placed in black cellophane bags and labelled. Masking tape was used to seal the sample bags. In preparing for analysis, soil and sediment sample were air dried and crushed afterwards and made to pass through a $2 \mathrm{~mm}$ sieve. These were then weighed and stored (four weeks) before they were eventually analysed. The storage allows for Radon and other short lived progenies to attain secular radioactive equilibrium before gamma spectroscopy (Prakash et al, 2007). The samples were stored in Marinelli sample containers as well.

All samples were placed in the Sodium-Iodide Detector and counted for 10 hours, analysis was carried out at the National Institute of Radiation Protection and Research (NIRPR) at the University of Ibadan, Ibadan. The instrument is a Model 802, coupled to Canberra Lead cylindrical shield of $10 \mathrm{~cm}$ thickness. Energy calibration used a set of International Atomic Energy Agency (IAEA) standard (known) sources of radionuclides within a well-defined energy range $(0.511-2.615 \mathrm{MeV})$. Computation of the photo-peak of each of the radionuclide was done using the firmware algorithm of the Multichannel Analyser. Specific activities were indirectly determined through the activities of their decay products. Net area after the correction for background in each photo peak was adopted in the computation of the activity concentration of each radionuclide of interest.

Table 1: Relative position of sample collection sites

\begin{tabular}{cl}
\hline Sample ID Number & Relative Position \\
\hline 1 & Port Harcourt Zoo area \\
2 & State School, Oginigba \\
4 & Shell Gutter, Rumubiakani \\
5 & Bridge area by the Zoo \\
6 & Bridge by the Slaughter \\
7 & Tekon area \\
8 & Eze's Palace Oginigba \\
9 & Pabod waste area \\
10 & Rumubiakani dump site \\
\end{tabular}

Data Analysis: The specific activities of the three long-lived radioactive elements (LLRE) will be subjected to non-parametric tests. This was because the sample set for this study area is small. The implication from this is that it would be wrong to assume that the dataset will be normally distributed, thus parametric test would be inappropriate. Spearman Rank Correlation was used to examine the relationship among the LLRE examined across the three substrates (Soil, Sediment and Water). Spearman rank R is similar to the Pearson productmoment correlation coefficient in relation to the variability accounted for by them. However, Spearman R is computed from ranks, details of the computation, power and efficiency can be found in the works of Gibbons and Chakraborti (2014) and Siegel and Castellan (1988).

Mann-Whitney $U$ test was employed in testing the difference between the substrates for each of the LLRE. This test is an alternative to the parametric ttest analysis for independent samples. It is the most powerful of all the non-parametric t-test analysis for 
independent samples, i.e. more sensitive than WaldWolfowitz runs test and Kolmogorov-Smirnov twosample test (StataCorp, 2011). This analysis allows testing whether there are differences between two groups without the assumption of normal distribution.

\section{RESULTS AND DISCUSSION}

Exploration of parameter association: Analysis of the soil, water and sediments radiometric parameters shows that four statistically significant associations could be found for the study area (Table 2).

Table 2: Summary of Spearman Rank correlation results

\begin{tabular}{lccc}
\hline Parameter & $\begin{array}{c}\text { Spearman - } \\
\mathrm{R}\end{array}$ & $\mathrm{t}(\mathrm{N}-2)$ & $\mathrm{p}$-level \\
& & \\
\hline Water ${ }^{40} \mathrm{~K}$ vs Soil ${ }^{232} \mathrm{Th}$ & -0.721 & -2.945 & 0.018 \\
Water ${ }^{238} \mathrm{U}$ vs Soil ${ }^{238} \mathrm{U}$ & -0.717 & -2.719 & 0.029 \\
Water ${ }^{40} \mathrm{~K}$ vs Sediment ${ }^{238} \mathrm{U}$ & -0.697 & -2.749 & 0.025 \\
\hline
\end{tabular}

A strong negative correlation was observed between specific activity of ${ }^{40} \mathrm{~K}$ in water samples and that of ${ }^{232} \mathrm{Th}$ in the soil across the study area. Similarly, specific activity of ${ }^{238} \mathrm{U}$ in water samples and that of soil samples displayed strong negative correlation across the area. There was also relationship between water and sediment related parameters. Specific activity of ${ }^{40} \mathrm{~K}$ (water) and that of ${ }^{238} \mathrm{U}$ (sediment) showed a strong negative correlation.

From the foregoing, it is evident that there is an inverse relationship between the specific activity of some of the LLRE in water and that of soil (mostly) and sediment. It must be noted that this observation only pointed at association and not causation. Thus, from the study area, LLRE species ${ }^{40} \mathrm{~K}$ in the water decreases, ${ }^{232} \mathrm{Th}$ (soil) and ${ }^{238} \mathrm{U}$ (sediment) specific activity increases (and vice versa). However, ${ }^{238} \mathrm{U}$ specific activity is quite unique with, water and soil showing inverse relationship. This correspondence was absent for any other species of LLRE.
Overall, it is obvious that there are other factors at play, i.e. affecting the fate of radionuclide in soils. For example, Essignton et al (1981) showed that changes in sorption due to, alteration of solubility and charge speciation influence the short or long term fate of radionuclides in soils. Edgington and Nelson (1986) also showed that interactions of radionuclides in the oceans or marine sediments could be described in terms of adsorption equilibrium. While effective equilibrium constant is a function of the redox properties, the complex forming ability, concentration of the stable element of the element considered as well as properties of the water body (concentration of ligands, surface and chemical properties). Moreover, Dar and El Saman (2014), shows that around the Jubal Strait (an important oil production and processing area along the Red Sea), there is a positive correlation between dissolved oxygen and the activity patterns of some LLRE while there is a negative correlation between these and $\mathrm{pH}$ and salinity.

To fully understand the interaction among the LLRE, there is need to collect more samples as well as data on environmental condition under which such data were collected. However, this result indicates that there are conditions present in the study area which favours inverse relationship as observed.

Exploration of differences across substrate specific activity: Water and Soil specific activities for the LLRE were compared to confirm if there is a difference between them. The mean rank for all the three LLRE were found to be higher for soil in comparison to that of water (Table 3). This is an indication that the specific activities of LLRE in water samples are generally lower than that of soil samples. This could be attributed to the ability of soils to hold on to the radionuclides (just like heavy metals) while in the case of water, there may be constant renewal and depletion due to the flow of the water body.

Table 3: Descriptive statistics of rank for soil and water samples

\begin{tabular}{clrrr}
\hline LLRE & Subsample & N & Mean Rank & \multicolumn{1}{c}{$\begin{array}{c}\text { Sum of } \\
\text { Ranks }\end{array}$} \\
\hline${ }^{40} \mathbf{K}$ & Water & 10 & 7.700 & 77.000 \\
& Soil & 10 & 13.300 & 133.000 \\
${ }^{232} \mathbf{T h}$ & Water & 10 & 7.000 & 70.000 \\
& Soil & 10 & 14.000 & 140.000 \\
${ }^{238} \mathbf{U}$ & Water & 9 & 5.000 & 45.000 \\
& Soil & 10 & 14.500 & 145.000 \\
\hline
\end{tabular}

Result of the Mann-Whitney U test (Table 4) shows that there is a significant difference between the LLRE specific activities in the soil and that of water. There is a highly significant different in specific activity of ${ }^{232} \mathrm{Th}(\mathrm{Z}=-2.646, \mathrm{p}=0.007)$ between water and soil sample. Similarly, a highly significant different was also observed for ${ }^{238} U(Z=-3.674, p=$ 0.000). 
Table 4: Test statistic results for differences between soil and water samples

\begin{tabular}{llll}
\hline \multicolumn{1}{c}{ Test Parameter } & ${ }^{40} \mathrm{~K}$ & ${ }^{232} \mathrm{Th}$ & ${ }^{238} \mathrm{U}$ \\
\hline Mann-Whitney U & 22.000 & 15.000 & .000 \\
$\mathrm{Z}$ & -2.117 & -2.646 & -3.674 \\
Exact Sig. [2*(1-tailed Sig.)] & 0.035 & 0.007 & 0.000 \\
\hline
\end{tabular}

This gave an indication that, across the study area the specific activities of these LLRE vary considerably across different substrates. While it could be argued that, the LLRE specific activity in the soils (are related to that of the geology of the area) should be similar to that of the water in the same water (comparatively). The result indicates that the shape of the distribution is different for all the LLRE across the two substrates.

Between water and sediment, a comparison of the rank mean (Table 5), shows that the mean rank of specific activities for the 3 LLRE were consistently higher in the sediment samples in comparison to the water samples. This observation is similar to what was obtained for soil and water - LLRE specific activity in water is about half of that recorded for soil samples.

Table 5: Descriptive statistics of rank for sediment

\begin{tabular}{clccc}
\multicolumn{5}{c}{ and water samples } \\
\hline LLRE & Subsample & $\mathrm{N}$ & Mean Rank & $\begin{array}{c}\text { Sum of } \\
\text { Ranks }\end{array}$ \\
\hline${ }^{40} \mathrm{~K}$ & Water & 10 & 7.400 & 74.000 \\
& Sediment & 9 & 12.890 & 116.000 \\
${ }^{232} \mathrm{Th}$ & Water & 10 & 7.700 & 77.000 \\
& Sediment & 10 & 13.300 & 133.000 \\
${ }^{238} \mathrm{U}$ & Water & 9 & 6.670 & 60.000 \\
& Sediment & 10 & 13.000 & 130.000 \\
\hline
\end{tabular}

Examination of the differences between these substrates (Table 6), shows that there are significant differences between water and sediment samples in relation to the specific activities of LLRE in the study area. This is contrary to the logical argument which suggests that, as sediments were carried by water (runoff) into the water body there should be a similarity in the distribution of the specific activity of the two. This is could be expected since samples were collected at the bank of the stream where there is less dilution of the effluent from the surrounding enterprises and industries.

Table 6: Test statistic results for differences between sediment and water samples

\begin{tabular}{lccc}
\hline Test Parameter & ${ }^{40} \mathrm{~K}$ & ${ }^{232} \mathrm{Th}$ & ${ }^{238} \mathrm{U}$ \\
\hline Mann-Whitney U & 19.000 & 22.000 & 15.000 \\
$\mathrm{Z}$ & -2.123 & -2.117 & -2.449 \\
Exact Sig. [2*(1-tailed Sig.)] & 0.035 & 0.035 & 0.013 \\
\hline
\end{tabular}

Mean ranks result for comparison between the soil and sediment samples' specific activities for the 3 LLRE are presented in Table 7. The mean rank of the specific activity of ${ }^{40} \mathrm{~K}$ across the soil samples was found to be lower than that of the soil. However, the opposite was recorded for ${ }^{232} \mathrm{Th}$ and ${ }^{238} \mathrm{U}$ i.e. mean ranks for soil is higher than that of sediment.

Table 7: Descriptive statistics of rank for sediment

\begin{tabular}{clrrr}
\multicolumn{4}{c}{ and soil samples } \\
\hline LLRE & Subsample & $\mathrm{N}$ & Mean Rank & \multicolumn{1}{c}{$\begin{array}{c}\text { Sum of } \\
\text { Ranks }\end{array}$} \\
\hline${ }^{40} \mathrm{~K}$ & Soil & 10 & 9.50 & 95.00 \\
& Sediment & 9 & 10.56 & 95.00 \\
${ }^{232} \mathrm{Th}$ & Soil & 10 & 12.10 & 121.00 \\
& Sediment & 10 & 8.90 & 89.00 \\
${ }^{238} \mathrm{U}$ & Soil & 10 & 11.85 & 118.50 \\
& Sediment & 10 & 9.15 & 91.50 \\
\hline
\end{tabular}

This result shows that the difference between soil and sediment specific activity is dynamic and radionuclide specific even though they are all LLRE. However, with the mean rank showing differences between the two substrates, it is thus necessary to confirm whether these differences are statistically significant.

Table 8: Test statistic results for differences between

\begin{tabular}{|c|c|c|c|}
\hline Test Parameter & ${ }^{40} \mathrm{~K}$ & ${ }^{232} \mathrm{Th}$ & ${ }^{238} \mathrm{U}$ \\
\hline Mann-Whitney U & 40.000 & 34.000 & 36.500 \\
\hline $\mathrm{Z}$ & -.408 & -1.209 & -1.021 \\
\hline Exact Sig. [2*(1-tailed Sig.)] & 0.720 & 0.247 & 0.315 \\
\hline
\end{tabular}

Result of Mann-Whitney U test (Table 8) shows that there are no significant difference between the soil and the sediment irrespective of the species of the radionuclide. This is an indication that while sediments are deposited and soils are more or less resident there is no difference between the gamma specific activities of LLRE for both across the study area.

Overall the results shows, that soil and water specific activities for LLRE across the study are different. This is contrary to expectation that the concentration of LLRE in the soil and water at same sampling point/area should be similar if not in values but in shape of the distribution. Sediments are carried by water, and it could be expected that the trend and pattern of LLRE in sediments and water should be similar. The opposite was observed, that there is a significant difference between the concentration of the LLRE in soil and water. This further shows that while there are differences in the chemical properties and half-lives of the radionuclides and as such leaching into the environment also occurs at different 
rates (Ames et al, 1978; Gäfvert and Færevik, 2005).

${ }^{40} \mathrm{~K}$ solubility in sediment is known to be higher than other LLRE (measured in the study) and this solubility varies with respect to the amount of organic matter and particle size of the soil (Harrison, 1999). Moreover, the concentration in surface water may be affected by climatic conditions, the oxidation state of the water (Ahmed et al, 2001). As such, we could attribute this significant difference in the concentration between solids (sediment and soils) and liquid (water) across the study area to this differences in the factors influencing their concentration.

A look at the difference between the solids (sediment and soils) show that soil and sediment are similar in their concentration of LLRE across the study area, the difference can be said to be least pronounced in ${ }^{40} \mathrm{~K}$ followed by ${ }^{238} \mathrm{U}$ and then ${ }^{232} \mathrm{Th}$. It is well established that the more fine-grained materials are in the soil or sediment, the high the concentration of radionuclides (Dar and El Saman, 2014; International Atomic Energy Agency, 1988). Furthermore, Ames et al., (1978) showed that ions in solution exist in dynamic equilibrium in soils, sediment and rocks, therefore any factor inherent in the solid matrix and the solution can influence the concentration of elements and their species in solution. And according to them $\mathrm{pH}$, cation exchange capacity, type and amount of soil minerals competing ion etc. influence this concentration. In light of this, it is no surprise that there are no differences between the concentration of these LLRE in the soil and sediment samples.

Conclusion: The study seeks to examine the association in specific activities of selected LLRE in the soil, water and sediment across an intensively used creek in an urban setting in Niger Delta. Furthermore, it seeks to examine differences among soil, water and sediment concentration of the LLRE in the study area. The result shows that there is a strong negative correlation between soil and water concentration of ${ }^{238} \mathrm{U}$ similarly strong negative association was found between Water ${ }^{40} \mathrm{~K}$ and Soil ${ }^{232} \mathrm{Th}$ as well as between Water ${ }^{40} \mathrm{~K}$ and Sediment ${ }^{238} \mathrm{U}$. This shows that there are underlying factors within the study area which brought about this association. And this requires further investigation.

In relation to the second research question, we can conclude that the solid samples (soil and sediment) are different from the liquid (water) samples with respect to their concentration of LLRE. This could be attributed to the differences in factors influencing the concentration of LLRE. Even though the samples are taken from areas with very little dilution effect, there are still differences between these two. As such, we posit that even though there is interaction between the two, the inherent attributes of the substrates confer differences in their ability to harbour LLRE. However, in the case of soil and sediment, no difference was found and thus the conclusion is, depending on the particle size, soil and sediment are not likely to be different in the concentration of LLRE especially around our study area. This study was carried out with a small dataset, it is thus suggested that more evidence will be required to further confirm the relationship and difference observed in this study.

\section{REFERENCES}

Ahmed, N., Abbady, A., El-Kamel, A., Steinhausler, F., and El-Arabi, A. (2001). Studies of natural radioactivity of some Egyptian rock phosphates. Indian Journal of Pure and Applied Physics, 39(9), 553-560.

Ames, L. L., Rai, D., and Kaufmann, R. F. (1978). Radionuclide interactions with soil and rock media. environment, 3, 153.

Dar, M. A., and El Saman, M. I. (2014). The interactions of some radioelements activity patterns with some hydrographic parameters at the petroleum and phosphate regions in the Red Sea, Egypt. Journal of Radiation Research and Applied Sciences, 7(3), 292-304. doi: http://dx.doi.org/10.1016/j.jrras.2014.03.005

Edgington, D. N., and Nelson, D. M. (1986). The chemical behavior of long-lived radionuclides in the marine environment (pp. 41-59). International Atomic Energy Agency (IAEA).

Essignton, E. H., Fowler, E. B., and Polzer, W. L. (1981). The Interactions of low-level, liquid radioactive wastes with soils: 2 . Differences in radionuclide distribution among four surface soils. Soil Science, 132(1), 13-18.

Gäfvert, T., and Færevik, I. (2005). Natural radioactivity in produced water from the Norwegian oil and gas industry in 2003: Statens Straalevern, Oesteraas (Norway).

Gibbons, J. D., and Chakraborti, S. (2014). Nonparametric Statistical Inference, Fourth Edition: Revised and Expanded: Taylor and Francis. 
Harrison, R. M. (Ed.). (1999). Understanding our environment: An introduction to environmental chemistry and pollution (3 ed.). London: Royal Society of Chemistry.

International Atomic Energy Agency. (1988). Assessing the impact of deep sea disposal of low level radioactive waste on living marine resources: International Atomic Energy Agency.

Lawal, O. (2009). Analysis of land use changes in the Thames Gateway: the change-pattern approach. (PhD), University of East London, London.

Lawal, O. (2014). Wasteful disposition: Analysis of municipal household waste using geodemographic classification. Waste Management and Research, 32(2), 170-174. doi: 10.1177/0734242x13519692

Niger Delta Development Commission. (2006). Niger Delta Regional Development Master Plan: NDDC.

Nwankwoala, H. O., and Omunguye, M. L. (2013). Geophysical Investigation for Groundwater in Borokiri and Eastern-Bye Pass Areas of Port Harcourt, Nigeria. Pacific Journal of Science and Technology, 14(1), 524-535.

Prakash, V., Narayana, Y., and Siddappa, K. (2007). Concentration of natural radionuclides in and around Padubidri on the coastal Karnataka, India. Journal of Radioanalytical and Nuclear Chemistry, 274(2), 367-372. doi: 10.1007/s10967-007-1124-y
Rubel, F., and Kottek, M. (2010). Observed and projected climate shifts 1901 and\#8211;2100 depicted by world maps of the Köppen-Geiger climate classification. Meteorologische Zeitschrift, 19(2), 135-141. doi: 10.1127/09412948/2010/0430

Short, K., and Stauble, A. (1967). Outline of geology of Niger Delta. AAPG bulletin, 51(5), 761-779.

Siegel, S., and Castellan, N. J. (1988).

Nonparametric Statistics for the Behavioral Sciences: McGraw-Hill.

StataCorp. (2011). Stata Statistical Software (Version 12). College Station, TX: StataCorp LP.

United Nations. Scientific Committee on the Effects of Atomic Radiation. (2000). Sources and effects of ionizing radiation: sources (Vol. 1): United Nations Publications.

Water and Sanitation Department. (2014). Appraisal report: Urban water sector reform and PortHarcourt water supply and sanitation roject. In M. Blomberg, E. El-Azizi, O. Dore and K. Ba (Eds.), Project Appraisal Report. Abidjan: African Development Bank Group.

World Nuclear Association. (2014, December 2014). Naturally-occuring radioactivte materials (NORM). Retrieved 5th january, 2015, from http://www.world-nuclear.org/info/Safety-andSecurity/Radiation-and-Health/NaturallyOccurring-Radioactive-Materials-NORM/ 